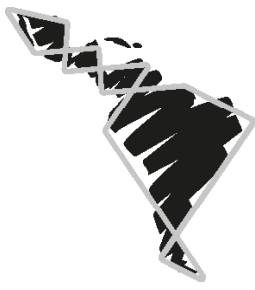

\title{
La ficción humanista de la historia: Reseña de la novela Culpeo de Miguel Baraona Cockerell
}

\author{
History's humanist fiction: Review \\ of Miguel Baraona Cockerell's novel \\ "Culpeo"
}

\section{A ficção humanista da história: Revisão do romance Culpeo de Miguel Baraona Cockerell}

\author{
María de los Ángeles Sancho Ugalde
}

\section{Resumen}

Esta reseña de la obra del escritor Miguel Baraona Cockerell (Culpeo, 2015, San José-Costa Rica: EUNA) intenta situar esta novela dentro de ciertos parámetros analíticos y, en especial, en relación con la narrativa de ficción histórica y al pensamiento humanista que este mismo autor ha expuesto en diversos trabajos.

Palabras claves: ficción, literatura, Historia/historia, humanismo, Luciano Cruz, Chile, Perú, Bolivia, Tierra de Fuego, Guerra del Pacífico (1879-1884), selk'nams.

Abstract

This review of the work by the writer Miguel Baraona Cockerell (Culpeo. 2015. San José-Costa Rica: EUNA), seeks to situate this novel within the analytical framework provided both by the study of historical fiction and the humanist though developed by this author in other works.

Keywords: Fiction, literature, History/history, humanism, War of the Pacific (1879-1884), Luciano Cruz, Chile, Peru, Bolivia, Tiera del Fuego, selk’nams.

1 Licenciatura en la Enseñanza del Español por la Universidad Nacional, egresada de la Maestría en Lingüística de la Universidad de Costa Rica. Académica, investigadora y extensionista en el Centro de Estudios Generales, Universidad Nacional. Nacionalidad: costarricense. 


\section{Resumo}

Esta revisão do trabalho do escritor Miguel Baraona Cockerell (Culpeo. 2015. San José-Costa Rica: EUNA), procura situar este romance dentro de certos parâmetros analíticos e, especialmente, em relação à narrativa de ficção histórica e pensamento humanista que este mesmo autor expôs em várias obras.

Palavras chave: Ficção, literatura, História / história, humanismo, Guerra do Pacífico (1879. 1884), Chile, selk'nams.

\section{Ficción, historia y humanismo}

La mirada retrospectiva a tiempos y eventos pasados ocupa, sin dudas, un lugar primordial en el desarrollo de la literatura. Obras enormes e inolvidables, o eternas dentro del ámbito de la existencia humana, como Guerra y paz, Historia de dos ciudades, Los pilares de la tierra, Lo que el viento se llevó, Capitán de mar y tierra, Waverley, Ivanhoe, La guerra del fin del mundo, Los miserables, José y sus hermanos, Doctor Zhivago, y un largo etcétera, han dejado huellas hondas en la memoria colectiva y se han instalado, muchas veces, como referentes retrospectivos más poderosos que los frutos académicos de la propia historiografía. A veces la novela histórica retrocede siglos, para intentar entregarnos una imagen más vívida, encarnada por personajes específicos y concretos, y en otras ocasiones, solo retrocede algunos años o décadas para reconstruir un flujo de eventos y un escenario pretérito pero aún fresco en la memoria de observadores o protagonistas vivientes. En cualquiera es de esos casos, se trata de un arte difícil y espinoso, pues cuando es un viaje a un pasado distante, la información suele ser más dispersa e incompleta, y se arriesga por parte del novelista, el incurrir en errores historiográficos importantes que tal vez sean severamente reprochados; o si es apenas un regreso a situaciones dentro de la escala temporal reciente de la vida humana individual, se trata de acontecimientos casi de seguro polémicos y cargados en la memoria colectiva de pasiones subjetivas, entre las que el literato deberá navegar con audacia y con la mayor honestidad intelectual; y aún así, siempre arriesgará atraer críticas, inquinas y hostilidades perdurables de parte de algún segmento del público lector e inclusive de los estudiosos del género.

Pero, a pesar de todos los pesares y escollos que siempre amenazan la viabilidad y aceptación pública y posiblemente de expertos de la ficción histórica, el género ha llegado para quedarse, teniendo millones de lectores y adeptos entusiastas, pues algo hay con la magia de la historia y del pasado cuando se les acerca en forma humana y particular a nuestro presente, que nunca dejará de estar en boga. El pasado, visto a través del cristal de la experiencia individualizada de protagonistas imaginarios pero factibles y convincentes, seguirá ejerciendo su fascinación sobre 
la imaginación contemporánea, sirviendo así de máquina del tiempo que puede transportarnos en forma casi personal de vuelta a aquellos acontecimientos que forjaron, y están forjando aún, la propia historia de nuestros días.

La conexión de estos dos tópicos -ficción e historia- con el humanismo reside en que ambas perspectivas tienen como foco central y muy predominante, el ser humano, su condición individual y social, y el marco existencial interno (subjetivo) y externo (mundo circundante). Y en esta confluencia esencial de temas y propósitos, la narrativa ficcional y la historia resultan ser vertientes complementarias del espíritu humano que unen fuerzas para desentrañar algunas de las grandes interrogantes que el humanismo se plantea también: isomos protagonistas de nuestro propio destino, o meras criaturas sometidas al arbitrio de grandes fuerzas que nos transportan como hojas al viento, o la intervención variable, complementaria, antagónica y alterna de estas dos posibilidades de nuestro quehacer?; ¡cuáles son los resortes esenciales de nuestra conducta: el espíritu humano, los intereses materiales, los imperativos ideológicos, el imperio de las normas e instituciones sociales, el poder de los sentimientos, los deseos más íntimos y secretos de nuestro ser, la luz de la razón, la malevolencia de los cálculos más crueles y mezquinos, los instintos de bondad y generosidad de los cuales se nutren ideales de solidaridad y altruismo, los sueños que nos elevan a la realización y/o a la desilusión o ambas cosas al mismo tiempo, etc.?

La historia no es otra cosa que el desenvolvimiento en el tiempo de nuestra naturaleza humana, su despliegue dramático y al mismo tiempo trivial en el enorme escenario de los siglos. Y cuando la narrativa de ficción se vuelca a explorar este teatro de lo humano en la cotidianeidad de años y años, esa obra espontánea, impredecible, y de infinita complejidad donde se despliega nuestro ser en toda su magnífica y también dolorosa realidad con el paso infinito de los días, se acerca indefectiblemente a los enigmas que desde milenios, los humanistas no han dejado de hurgar en la búsqueda de una certeza esperanzadora sobre la humanidad.

El literato que retorna al pasado y escudriña aquello que solo vive ya en el recuerdo que se disipa, siempre lo hace, consciente o inconscientemente, para entender mejor al ser humano, y también, para sostener en la noche de los misterios de nuestro presente, la luz temblorosa de una vela de esperanza, que se niega a apagarse a pesar de los vientos a menudo tempestuosos de la historia. El literato histórico desea encontrar algún tipo de redención humana, y en el mejor de los casos resurrección, en esos tiempos idos en que quizás mujeres y hombres comunes hicieron algo noble y trascendente, aunque solo fuera en un fugaz instante de amor, piedad, entrega, nobleza y empatía. Y en eso, sus propósitos abiertos u ocultos, conscientes o inconscientes, se fusionan en un estrecho abrazo con los 
del humanista: ambos ratifican aquel lugar común que destaca que la esperanza es lo último que muere en el espíritu humano. Pues cuando ella muere, se acaban los sueños, y nuestra condición se torna sombría e inhumana. Sueños y esperanza, lo admitan o no, son los materiales fundamentales con los que trabajan el literato y el humanista. Y la Historia (así con mayúscula), bien considerada a través de la vida diaria (la historia, así con minúscula) del mortal de la calle, provee materia prima interminable para tal elevada empresa de sueños y esperanzas.

El humanismo especula sobre la naturaleza de nuestra especie, para intentar llevar agua a los molinos imaginarios de una añorada, y quizás posible perfectibilidad del ser humano. El literato histórico, por su parte, quiere ver nuestro sino individual y colectivo encarnado en las tramas específicas de individuos concretos bregando en el torbellino de la Historia, y posiblemente, al igual que el humanista, para desenterrar del lodazal con frecuencia sangriento de la barbarie, trozos preciosos de amor, bondad, gentileza, humildad, abnegación, heroísmo, sacrificio, fraternidad, etc.; es decir, para rescatar del naufragio de la Historia, las diminutas historias de protagonistas anónimos cuyas vidas desconocidas y olvidadas, son el bello, indispensable y nunca bien honrado sostén de los sueños esperanzados en el destino de la humanidad.

\section{Una novela humanista y esperanzadora sobre la tragedia de la Historia}

Culpeo es una novela histórica, enmarcada en situaciones latinoamericanas y eventos reales de nuestro pasado (y aún presente, si uno considera las relaciones contemporáneas entre los Estados de Chile, Bolivia y Perú), en ella Baraona nos presenta múltiples universos, donde cohabitan la realidad y la ficción, donde subyacen realidades e identidades literarias nuestroamericanas. Y para ello tuvo que realizar una investigación exhaustiva en archivos nacionales de los países en conflicto y recopilar cartas de soldados y otros materiales primarios, nacidos del corazón y la mente de quienes participaron en la guerra:

Los periódicos de la capital amanecieron con grandes titulares anunciando la declaratoria chilena de guerra a Perú y Bolivia, por mantener un pacto secreto en contra de los intereses del Estado de Chile [...] El 14 de febrero [de 1879] fuerzas militares chilenas al mando del coronel Emilio Sotomayor ocuparon el puerto boliviano de Antofagasta [...] Así comenzaría uno de los conflictos bélicos más prolongados, sangrientos y de dramáticas consecuencias en la historia de Latinoamérica (Baraona, 2015, pp. 61-62).

Según el autor, la obra nace a partir de cuatro situaciones significativas: 
1. Baraona es de nacionalidad chilena, aunque en sus momentos de angustia se define como apátrida y antinacionalista, y en su infancia y juventud vivió en Bolivia y Perú, por lo que considera a estos últimos como países hermanos y entrañables, tanto como su propio país nativo.

2. Cree que Chile tiene una deuda histórica con Bolivia y Perú por la invasión de las tropas chilenas y la Declaratoria de guerra en 1879, el período más sangriento fue cuando miles de campesinos fallecieron en la Campaña de la Breña o de la Sierra, que inició en 1881. Grandes y terribles batallas como las de Chorrillos y Miraflores en las que fallecieron muchos miles de hombres, y la Campaña de la Breña, son parte de la Guerra del Pacífico (1879-1884) que se da por la importancia económica que asume en el siglo XIX la explotación del salitre (un gran fertilizante natural) ${ }^{2}$ por parte de empresas chilenas y británicas en territorio boliviano (aproximadamente un $90 \%$ de los mineros eran campesinos chilenos que se trasladan a trabajar a la región salitrera), y que ven amenazados sus intereses cuando el gobierno boliviano decide aumentar en forma unilateral los impuestos a la minería calichera, ${ }^{3}$ rompiendo un injusto tratado anterior firmado por un régimen corrupto.

3. Su bisabuelo Javier Baraona Calvo fue almirante en la famosa Batalla Naval de Angamos -en que el temible navío de guerra peruano El Huascar fue capturado y en que falleció el héroe peruano el Almirante Miguel Grauy luego sería condecorado dos veces por su heroica participación en las Batallas de Chorrillos y Miraflores (personaje histórico que aparece en la novela en la página 88).

4. Por último, la influencia en su literatura de su formación como antropólogo. Y como latinoamericano errante que ha vivido en muchos países, llevado a ello, sobre todo, por las fuerzas mismas de la Historia y de su propia y muy particular historia.

\section{Literatura en función social}

El autor utiliza la literatura como un medio para la denuncia de conflictos bélicos, problemáticas sociales (el genocidio de los selk' nams, ocupa un lugar narrativo importante en la segunda parte de la novela), políticas y de sobreexplotación de la naturaleza contextualizadas en Chile, Perú, Bolivia y Argentina a finales del siglo XIX.

2 El salitre es una mezcla de nitrato de potasio (KNO3) y nitrato de sodio (NaNO3). Se encuentra naturalmente en grandes extensiones de América del Sur, principalmente en el salar de Uyuni en Bolivia y en la zona norte de Chile, con espesores de hasta los 3,6 metros.

3 Caliche es el nombre que se le da al salitre en la región donde se explota. 
Los personajes se enfrentan a diversas problemáticas de explotación, discriminación e incluso exterminio, pero lo más severo de la primera mitad de la novela, tiene que ver con gobiernos que buscan soluciones bélicas a conflictos internacionales complejos, situaciones de género, de pobreza, abuso de poder, autoritarismo, etnia, identidad, entre otros. A la vez, la novela nos muestra las muchas otras facetas normales y soportables, e incluso admirables, de la vida diaria de una constelación de personajes que alimentan una narrativa que hace de Culpeo no solo una obra de denuncia social y política acorde con una determinada perspectiva ideológica, sino un relato sobrio y emotivo, al mismo tiempo, de la plenitud de la vida con todas sus luces y sombras:

En estas últimas batallas [Enzo Sanpietri] había dirigido a un batallón que estaba conformado en su mayoría por indios serranos, traídos a la fuerza por la leva, que en su mayoría apenas hablaban español y poco entendían de lo que estaba sucediendo y solo deseaban regresarse cuanto antes a sus aldeas y pueblos ancestrales, y que, para más remate, estaban con frecuencia armados con fusiles y carabinas para las que poseían un parque de municiones equivocadas. Aún antes de comenzar los combates, el capitán Sanpietri estaba dominado por malos augurios y un sentimiento deprimente de que la derrota era segura e inminente. Y no se equivocaba: las abismales diferencias discriminatorias de tipo étnico que plagaban al Perú, se reflejaban también en sus fuerzas armadas y en su incapacidad para levantar una defensa apropiada ante el avance de las tropas invasoras (Baraona, 2015, p. 51).

Los personajes de Culpeo han sufrido dolor, terror, brutalidad, pero eso no los sustrae completamente de vidas que podríamos llamar "normales" y a menudo placenteras. Los seres humanos son víctimas de la guerra, de la barbarie, injusticia, violación del derecho a la vida, la libertad y la integridad física, pero también aman, conviven, tienen éxitos y fracasos diversos, y existen en su propio universo espacio-temporal con la misma naturalidad, plenitud y abandono con que nosotros lo hacemos hoy en nuestras propias vidas. No es una obra sobre el sufrimiento y la miseria humana, aunque estos fenómenos sean consustanciales a la experiencia de la humanidad, sino que intenta rescatar el pasado en toda su maravillosa, contradictoria y compleja riqueza.

Esta novela histórica es una forma de lucha: imágenes de dolor, saqueos, violaciones a mujeres, terror en testigos de sobrevivencia y escritura de la memoria; pero es también la crónica de muchas vidas con diferentes destinos y derroteros, que se mueven y entrelazan con otras experiencias individuales distintas, formando así un universo existencial colectivo y común. 
Por otra parte, Culpeo es no solo una crítica a desigualdades abismales e injusticias sociales taxativas de las sociedades latinoamericanas del siglo XIX, sino que es una denuncia de la guerra impulsada por oligarquías criollas que apelan al nacionalismo ciego y a menudo ingenuo y simplista de los pueblos, para lograr fines egoístas a costa de la manipulación y sacrificio de muchos. Pero lo que puede ser denuncia social en el terreno de la historiografía que aborda la Historia, cobra ribetes más trágicos, más dichosos, y más inmediatos y más carnales cuando se trata de protagonistas palpitantes de vida concreta y natural, es decir, como actores centrales de la(s) historia(s) que ellas y ellos mismos escenifican:

[Piedrón] vio al oficial con su espada desenvainada en una mano y con su revólver en la otra [...] pero esa imagen duró solo un segundo en sus retinas, pues de inmediato quedó cubierto en el rostro y el torso por la sangre y los restos de otro soldado chileno cuya cabeza estalló a solo un metro delante de él. El cuerpo se retorció como un muñeco que se desbarata, mientras daba un paso más antes de caer al suelo polvoroso y empinado de la colina (Baraona, 2015, p. 89).

[...] Por sobre el cuello ensangrentado de la camisa blanca sucia ahora y ensangrentada del trompeta [Charrusco], se asomaba el cartílago rosado de su tráquea destrozada como una manguera cortada con un cuchillo sin filo, y el sonido gorgoreante y sibilante puso a temblar al mismo Luciano (Baraona, 2015, p. 187).

[...] Numerosas mujeres jóvenes solteras y casadas eran violadas por soldados chilenos, quienes gozaban de casi total impunidad debido a la indiferencia de Letelier hacia esos desmanes (Baraona, 2015, p. 138).

La obra literaria Culpeo es una obra de ficción, con muchas de sus situaciones nacidas solo de la imaginación del escritor, pero también es referencial y pretende alcanzar un valor de verdad (momentos marcados por funciones explícitamente referenciales a hechos y datos "reales"). Los enunciados tienen una correspondencia con la realidad. Apuntan hacia hechos que han ocurrido en el pasado y cuya autenticidad puede ser sometida a pruebas de veredicción (por ejemplo: nombres propios de lugares, personajes históricos, circunstancias históricas denotativas, eventos oficialmente consignados, documentos primarios como cartas, periódicos y diarios de vida de la época, etc.).

Por ejemplo, son personajes históricos: el Teniente coronel Ambrosio Letelier quien dirige las tropas chilenas y protagoniza una intensa campaña para derrotar al general rebelde Avelino Cáceres de las tropas peruanas. 
En los escenarios naturales y sociales de la segunda mitad de la novela, cuando el protagonista principal, Luciano Cruz, es contratado por los grandes estancieros y criadores de ovejas de Tierra del Fuego para exterminar una extraña bestia que asola el ganado lanar, otra referencia histórica es la explotación de oro en la gran isla austral hacia 1884, cito:

Julius Popper, quien había mantenido intensa correspondencia con los miembros más conspicuos de la recientemente creada Sociedad Explotadora de Tierra del Fuego, los había instruido a la distancia en cómo debían acabar con la "amenaza" que representaban los salvajes de la isla grande para que el progreso y la civilización pusieran pie firme de una buena vez en esa región (Baraona, 2015, pp. 342-343).

Popper fue un ingeniero y aventurero rumano, judío, nacionalizado y asentado en Argentina. Contratado por la Sociedad Explotadora de Tierra del Fuego, fue el orquestador y uno de los principales partícipes del exterminio de los indígenas selk'nams que habitaron Tierra del Fuego durante milenios antes de la llegada de los primeros colonos chilenos, argentinos y europeos.

En la obra, hay un carácter desmitificador presente en los personajes Luciano Cruz Marqués (personaje principal conocido como el Huaso Rucio) y Uruk'mapi (indígena selk'nam), quienes nunca pierden consciencia de su constitución social y de su constante lucha por la liberación, lo cual concede una significación política indudable: las luchas étnicas y de clases:

Los cadáveres de hombres, mujeres y numerosos niños estaban hinchados a pesar del frío, lo que hizo pensar a Luciano que llevaban al menos unos dos o tres días muertos. Estaban casi completamente desnudos, como si hubieran sido despojados de sus pieles, quizás para robarlas y luego venderlas a los excelentes precios que se podían obtener por ellas. Todos los cuerpos exhibían una o más heridas que parecían de bala, y a poco andar en ese macabro escenario, se dieron cuenta que les habían cortado una de las manos a los selk'nam que yacían allí como una suerte de ofrenda monstruosa a alguna deidad sedienta de sangre y de sufrimiento humano (Baraona, 2015, p. 390).

[...] No fue sino pocos días antes de que Luciano y su grupo llegaran al campamento devastado del clan del "fuego en la montaña" por los europeos, quienes ya estaban por levantar campamento y "regresar a la civilización", como decían ellos al referirse a su pronto retorno a Europa, habían decidido asaltar a los desprevenidos selk'nam y cobrar la jugosa recompensa que se pagaba por cada individuo asesinado. Con pruebas de las muertes ocasionadas, que solían ser orejas, dedos o manos, habían 
calculado que podían obtener, al menos, un 30\% de lo que conseguirían con el oro que habían recolectado (Baraona, 2015, p. 395).

\section{Simbolismo de Culpeo}

"Del mapudungún, culpeu. En Chile, es una especie de zorro grande y oscuro". En la novela, Culpeo es símbolo de la resistencia de los pueblos aborígenes, rebeldía primigenia del desarrollo capitalista, y de la resiliencia del mundo natural ante el avance depredador de la colonización europea. Fuerza sobrenatural de justicia ancestral: es el Culpeo que Luciano quiere cazar, el que los lleva a vengar la masacre anteriormente citada hacia los selk'nams. Es el mundo prístino y en estado de natura de la isla grande, que al igual que los pueblos andinos del Perú, aún separados en parte del desarrollo capitalista que se gesta en el corazón urbano de su país, pervivía en los márgenes de una civilización voraz y que ya avanzaba sobre él con energía devastadora. Pero aún en el corazón de esta tormenta que se avecina sobre los desprevenidos objetos de su furia inminente, hay individuos de estos "mundos olvidados" e inocentes, que poseen intuición, e incluso a veces preclara consciencia, de los enormes desafíos y peligros que se ciernen sobre su universo ancestral, y deciden sobrevivir a toda costa para que aquel ámbito del que son producto y representan, se perpetúe aunque apenas sea mediante su simple existencia física. Situaciones limítrofes, que en numerosas instancias extremas de la Historia, conducen a sus víctimas a una simple y brutal conclusión: todo lo que puedo hacer en este momento, es resistir para subsistir físicamente a nivel individual, y así al menos garantizar ese muy mínimo nivel de perpetuación de un grupo humano y su identidad. Es de otra forma, el judío o el gitano, o el comunista, luchando por mantenerse vivos en condiciones deplorables en los campos de exterminio nazis. O el disidente, languideciendo pero intentando vivir a pesar de todas las penurias e ignominias en un campo de trabajo forzado en la Siberia soviética.

Y para enfatizar aún más las absurdas ironías de la toponimia arbitraria y las denominaciones coloniales europeas y occidentales de los inframundos salvajes, el Culpeo, no es realmente un culpeo, sino una bestia casi mitológica que en el transcurso de la narración va mutando poco a poco en una criatura tan enigmática como formidable e inmortal: formidable e inmortal como ese mundo indomable que es el extremo más austral del continente americano. Al mismo tiempo que Culpeo no es un culpeo en realidad, sino otra cosa desconocida, aterradora y feroz, los llamados patagones no son patagones, sino los selk'nams, un grupo humano hermoso e indomable de un inframundo salvaje, y que desaparecerá dejando apenas la tenue estela de una leyenda cuyo enigma todavía nos embruja y persigue, como un espíritu errante y en pena que nunca desaparecerá por completo. 
Moviéndose entre las dos antípodas geográficas de ese naciente país en formación en el siglo XIX llamado Chile, entre la expansión simultánea de esa nación hacia el norte desértico y hacia el gélido y fecundo extremo austral, Culpeo presenta también una visión panorámica de los motivos, mecanismos, y consecuencias existenciales de este proceso sobre individuos atrapados en esta Historia, que los supera y de la que, sin embargo, no son ajenos. Y en este esfuerzo narrativo, están en juego, posiblemente, otras motivaciones intelectuales del autor.

A nuestro parecer, la propuesta de la obra literaria Culpeo está en concordancia con los enunciados del Nuevo Humanismo, publicados y promovidos por Baraona:

El Nuevo Humanismo se distingue por oponerse a:
a) Todo resabio colonial del pasado [...].
b) Toda forma de sexismo.
c) Toda forma de clasismo.
d) Toda forma de racismo.
e) Toda forma de explotación/destrucción -a menudo irreversible- de la naturaleza en aras del lucro y la acumulación de capital.

El Nuevo Humanismo propone:

a) Una sociedad global libre de toda desigualdad, asimetría y discriminación internacional.

b) Igualdad de género en derechos y oportunidades.

c) Reducción de la desigualdad social.

d) Una sociedad sin prejuicios ni discriminación étnica y racial, y sin xenofobia.

e) Una sociedad en la que la libertad y la integridad moral y física del ser humano no esté supeditada al materialismo extremo, a la tecnología a ultranza y al lucro.

f) Una relación armoniosa y sostenible entre sociedad y ambiente (Baraona y Mata, 2015, pp. 50-51). 


\section{Conclusiones}

Como conclusión, la obra en análisis tiene un valor comunicativo intencional, para que los receptores asumamos la verdad del discurso o el mensaje. Frente a las formas discursivas de denuncia, combatividad, acusación y desafío, se encuentran los jueces: somos nosotros como lectores quienes tenemos la última palabra y la sentencia. Narrador y público lector entrarán así en ese diálogo silencioso e imaginario, y que según Mijaíl Bajtín el gran estudioso ruso de la literatura, ${ }^{4}$ es de manera inescapable uno de los leitmotiv más poderosos en la configuración de toda obra literaria. Cada receptor, no obstante, entrará en un diálogo propio y específico con la obra, planteando sus propias interrogantes y sus propios juicios ante la trama de múltiples aristas que se despliegan en Culpeo.

La narrativa de Baraona en Culpeo es de carácter polifónico (numerosas vidas y voces individuales que dejan su eco en las páginas de la novela) y multisémico (una estratificación de numerosos niveles semióticos, entre los cuales no hay ninguno que sea predominante o hegemónico, sino que se van presentando, a propósito, entreverados y sin una jerarquía discernible). No es, por ende, una novela política ni social en el sentido estricto de estos conceptos, ni tampoco una narrativa de situaciones personales con escaso trasfondo general, sino que es más bien un mosaico heterogéneo y hasta cierto punto ecléctico, de sugerencias apenas susurradas algunas veces, y en otras, lanzadas al viento como un alarido silencioso al estilo de la obra pictórica de Edvard Munch (1863-1944), ${ }^{5}$ en las que se "disecciona el alma" de los sujetos que aparecen en la novela (las historias), al mismo tiempo que se les sitúa en el enorme flujo sobredeterminante de la Historia.

Pero en términos más poéticos, diríamos que esta novela de Baraona, así como otras recientes, han sido gestadas dentro de una visión literaria que él mismo ha denominado como "realismo existencial", ${ }^{7}$ y que otro inolvidable escritor ha definido así en su propio lenguaje, refiriéndose a los meandros laberínticos de la Historia y su representación literaria:

It was the best of times, it was the worst of times, it was the age of wisdom, it was the age of foolishness, it was the epoch of belief, it was the epoch of incredulity, it was the season of Light, it was the season of Darkness, it was the spring of hope, it was the winter of despair, we had everything before us, we had nothing before

\footnotetext{
4 Ver: Mijaíl Bajtín. 1986. Problemas literarios y estéticos. México: FCE.

5 Ver: Edvard Munch, El grito, 1893.

6 Como el propio Edvard Munch solía definir su propia obra pictórica, señalando que era una disección de almas.

7 Ver: Miguel Baraona Cockerell. 2011. Diez ensayos críticos. San José-Costa Rica: Editorial Germinal.
} 
us, we were all going direct to Heaven, we were all going direct the other way - in short, the period was so far like the present period [...] (Dickens, 1859, p. 15).

Era el mejor de los tiempos, era el peor de los tiempos, era una edad de sabiduría, era una edad de locura, era la época de las creencias, era una época de incredulidad, era la estación de la Luz, era la estación de la Oscuridad, era la primavera de la esperanza, era el invierno de nuestra desesperanza, teníamos todo delante nuestro, no teníamos nada delante nuestro, íbamos a irnos todos al Paraíso, e íbamos todos en la dirección contraria -en breve, el período era hasta ahora como nuestro presente ${ }^{8}[\ldots]$

\section{Referencias}

Bajtín, M. (1986). Problemas literarios y estéticos. México: FCE.

Baraona, M. (2011). Diez ensayos críticos. San José: Editorial Germinal.

Baraona, M. (2015). Culpeo. San José: EUNA.

Baraona, M. y Mata, E. (enero-junio 2015). "Los Estudios Generales como pedagogía multidisciplinaria en vías a la interdisciplina" en Revista Nuevo Humanismo, Vol. 3, No. 1, pp. 39-53.

Dickens, Ch. (1859). The Tale of Two Cities. London: Chapman \& Hall.

Recibido: $17 / 7 / 2017$

Aceptado: 14/3/2018

8 Ver: Charles Dickens. 1859. The Tale of Two Cities. England, p. 15. (Traducción nuestra). 